\title{
ACID-BASE STUDIES IN ELECTIVE CAESAREAN SECTIONS DURING EPIDURAL AND GENERAL ANAESTHESIA
}

\author{
Gordon S. Fox, M.D., F.R.C.P.(c) ANd Germain L. Houle, M.D., F.R.C.P.(c)*
}

Altrough great strides have been made in the reduction of perinatal mortality and morbidity, this problem occurs daily in delivery rooms throughout North America. In 1965, Cate and Nelson, ${ }^{1}$ in reviewing 965 caesarean sections found double the neonatal mortality after operative delivery, compared to vaginal delivery ( 3.4 per cent vs 1.7 per cent). A study published by the Ontario Department of Health, ${ }^{2}$ revealed a perinatal mortality rate of 47.8 per 1,000 elective caesarean sections. This is more than double the rate for cephalic vaginal delivery. Further, this study revealed that during all caesarean sections the perinatal mortality during general anaesthesia was 57.9 per 1,000 births while this number was 26.0 with conduction anaesthesia. The incidence of infant depression per 100 live births was 22.9 and 9.5 during general and conduction anaesthesia respectively.

A great many investigators have been interested in the effects of general and conduction anaesthesia on maternal and foetal acid-base parameters. Low, ${ }^{3}$ compared the acid-base status of the newborn infant delivered by elective caesarean section during epidural and general anaesthesia. Other authors ${ }^{4}$ have compared spinal versus epidural anaesthesia. Observations on the use of nitrous oxide, oxygen and succinylcholine anaesthesia, ${ }^{5,6}$ and epidural ${ }^{7}$ anaesthesia have been published.

We present observations on three groups of thirteen parturients and neonates at delivery during elective caesarean section. One group received thiopentone, nitrous oxide:oxygen and succinylcholine. The other 26 patients received epidural anaesthesia. Results of acid-base and metabolic studies of both mother and infant are discussed, and conclusions are drawn regarding which of these commonly used techniques is preferred.

\section{METHODS}

Thirty-nine women who received anaesthesia for caesarean section were studied. Thirteen patients received general anaesthesia while twenty-six were given epidural analgesia. One half of the patients who received epidural anaesthesia breathed 100 per cent oxygen via a Magill circuit and face mask for at least ten minutes before delivery.

Premedication consisted of atropine sulphate $0.4 \mathrm{mg}$ intramuscularly one hour prior to operation.

\section{Epidural anaesthesia}

With the patient in the sitting position a No. 16 gauge Tuohy needle was inserted into the epidural space between the third and fourth lumbar vertebrae

Royal Victoria Hospital, Montreal, Quebec, Canada 
using the loss of resistance technique. ${ }^{8}$ Three millilitres of sterile saline were injected through the needle to open the epidural space, and a polyvinyl catheter was inserted one needle-length. The patient was then placed in the supine position. A No. 19 gauge Butterfly needle was placed in a radial artery after local infiltration of the overlying skin with $0.2 \mathrm{cc}$ of 1 per cent procaine. An intravenous infusion of 5 per cent glucose in water was started in the opposite arm.

After a sample of heparinized arterial blood was obtained for control studies, analgesia was initiated by injecting 2 per cent lidocaine with 1:200,000 epinephrine through the epidural catheter.

\section{General anaesthesia}

Prior to induction of anaesthesia, an intravenous infusion of 5 per cent glucose in water was started, and the radial artery was cannulated in the same manner as in the epidural group. A sample of heparinized arterial blood for control studies was obtained.

All patients were pre-oxygenated with 100 per cent oxygen for three minutes through a Magill circuit and face mask. The patients were induced with a "sleep" dose of 2.5 per cent thiopentone, followed by intravenous succinylcholine, $1 \mathrm{mg} /$ $\mathrm{kg}$ body weight to facilitate endotracheal intubation. Respiration in all patients was controlled using a Bird Mark vin respirator. Utilizing a Wright respirometer, tidal volumes of approximately $7.5 \mathrm{cc} / \mathrm{kg}$ with respiratory rates of $16-18$ per minute were established. The respirator was adjusted as required to maintain necessary tidal volumes. Anaesthesia consisted of nitrous oxide:oxygen (5:2 litres) and an infusion of 0.1 per cent succinylcholine to produce adequate muscle relaxation.

At delivery a heparinized sample of maternal arterial blood was obtained in all groups. A doubly clamped section of umbilical cord was acquired prior to placental separation.

Maternal control and delivery samples were placed in ice and analysed within the hour for arterial oxygen and carbon dioxide tensions, and $\mathrm{pH}$, from which standard bicarbonate and base excess were derived. Blood gas analyses were obtained on umbilical venous and arterial blood specimens.

The condition of the infants was rated by Apgar scores ${ }^{9}$ at one and five minutes after birth. The time from delivery to sustained rhythmic respirations (TSR) in each infant was noted. ${ }^{10}$

The elapsed time from induction of anaesthesia was recorded (T-D). Blood pressure was registered throughout surgery, using a sphygmomanometer cuff and auscultation. Control, 5 minute post induction, and delivery mean blood pressures were calculated using the formula $\frac{2 \mathrm{Ps}+3 \mathrm{Pd}}{5}$ where Ps and Pd are systolic and diastolic pressures respectively. Three to six mg of methamphetamine were given intravenously when a vasopressor was required.

Foetal blood samples were placed in ice and analysed within the hour in dupli* A Abbot Laboratories 
cate for $\mathrm{pH}$ using the micro-Astrup method. ${ }^{11}$ Carbon dioxide tension and base excess were obtained with the aid of the Siggaard-Andersen nomogram. ${ }^{12}$ Oxygen tensions were determined with a Clark electrode. ${ }^{13}$

Maternal blood samples were analysed in duplicate for $\mathrm{pH}, \mathrm{Po}_{2}, \mathrm{PCO}_{2}$, using an Instrumentation Laboratories Inc analyser, Model 113. Standard bicarbonate and base excess were determined with the Siggaard-Andersen nomogram. ${ }^{12}$

\section{Statistical methods}

A discriminant analysis of the foetal results obtained from the three regimes of anaesthesia, was carried out using the BMD program $07 \mathrm{M}$. It was clear from this that the two discriminant functions were initially separating the general anaesthetic group of neonates from the epidural groups, and only secondarily, and virtually independently, distinguishing the two epidural series. The analysis was carried out again in an orthogonal fashion using the BMD program 02R to allow examination of the discriminants at various steps. In addition a discriminant analysis was carried out utilizing maternal values.

\section{Results}

Table I indicates the mean body weight, mean dose of thiopentone, mean time from injection of thiopentone or lidocaine to the moment of delivery (T-D). The mean blood pressure prior to initiation of anaesthesia, 5 minutes after induction and at delivery are also shown in Table I. In both epidural series at the 5-minute

\section{TABLE I}

The Mean Body Weights, Dose of Thiopentone on Lidocaine, Blood Pressures, and Elapsed Time to Delivery $(\mathrm{T}-\mathrm{D})$ in the Three Groups of Patients $(\quad)= \pm s D$

\begin{tabular}{|c|c|c|c|}
\hline & EPIDURAL-OXYGEN & EPIDURAL-AIR & GENERAL ANAESTHESIA \\
\hline $\begin{array}{l}\text { Mean Maternal Weight } \\
\qquad(\mathrm{kg})\end{array}$ & $66(10)$ & $73(11)$ & $69(11)$ \\
\hline $\begin{array}{c}\text { Mean Dose Thiopentone } \\
(\mathrm{mg})\end{array}$ & -- & -- & $219(55)$ \\
\hline $\begin{array}{l}\text { Mean Dose Lidocaine } \\
\text { (mg) }\end{array}$ & $310 \quad(32)$ & $316(25)$ & --- \\
\hline $\begin{array}{c}\text { Mean Blood Pressure } \\
\left(\begin{array}{c}(\mathrm{mm} H \mathrm{H}) \\
\text { Control }\end{array}\right. \\
5 \mathrm{~min} \text {. Post Induction } \\
\text { Delivery }\end{array}$ & $\begin{array}{ll}93 & (13) \\
76 & (14) \\
90 & (12)\end{array}$ & $\begin{array}{l}94(12) \\
70(9) \\
90(9)\end{array}$ & $\begin{array}{l}95(30) \\
99(18) \\
99(16)\end{array}$ \\
\hline $\begin{array}{l}\text { Time to Delivery- } \\
\text { Minutes (T.D.) }\end{array}$ & $28.8(11.0)$ & $26.0(6.2)$ & $20.9(6.0)$ \\
\hline
\end{tabular}


mark, mean blood pressure decreased appreciably from control levels. Prior to delivery, the blood pressure was easily corrected to pre-operative levels by left uterine displacement and/or intravenous methamphetamine 3-6 mg intravenously. The $\mathrm{N}_{2} \mathrm{O}: \mathrm{O}_{2}$ group did not reveal this tendency towards hypotension.

Mean control and delivery maternal arterial blood-gas determinations are shown in Table II. Discriminant analysis of the control variables reveals that the three groups of patients were comparable prior to anaesthesia. Similar analysis of the delivery variables showed that the $\mathrm{PO}_{2}$ of the epidural-oxygen group and

TABLE II

The Results of Maternal Blood-Gas Analysis in the Three Series of

Patients ()$= \pm \mathrm{SD}$

MEAN METERNAL ARTERIAL BLOOD-GAS ANALYSIS

\begin{tabular}{|c|c|c|c|c|c|c|}
\hline & \multicolumn{3}{|l|}{ CONTROL } & \multicolumn{3}{|l|}{ DELIIVERY } \\
\hline & $\begin{array}{l}\text { EFIDLURAL- } \\
\text { OXYGEN }\end{array}$ & EPIDURAL-AIR & $\begin{array}{l}\text { GENERAL } \\
\text { ANAESTHESIA }\end{array}$ & $\begin{array}{l}\text { EPIDURAL - } \\
\text { OXYGEN }\end{array}$ & EPIDURAL-AIR & $\begin{array}{l}\text { GENERAL } \\
\text { ANAESTHESIA }\end{array}$ \\
\hline $\begin{array}{l}\mathrm{Po}_{2} \\
M M \mathrm{HG}\end{array}$ & $80(11)$ & $76(8)$ & $81(11)$ & $364(111)$ & $75(12)$ & $104(42)$ \\
\hline $\begin{array}{l}\mathrm{PCO}_{2} \\
\mathrm{MM} \quad \mathrm{HG}\end{array}$ & in (9) & $28(6)$ & $25(5)$ & $29(5)$ & $28(5)$ & $32(4)$ \\
\hline $\mathrm{pH}$ & $7.440(.036)$ & $7.465(.061)$ & $7.490(.066)$ & $7.424(.043)$ & $7.431(.083)$ & $7.383(.081)$ \\
\hline $\begin{array}{l}\text { BASE } \\
\text { EXCESS } \\
\text { MEd/L }\end{array}$ & $-4.146(3.221)$ & $-2.980(1.816)$ & $-2.762(2.767)$ & $-4.046(2.430)$ & $-4.753(2.952)$ & $-4.946(4.101)$ \\
\hline
\end{tabular}
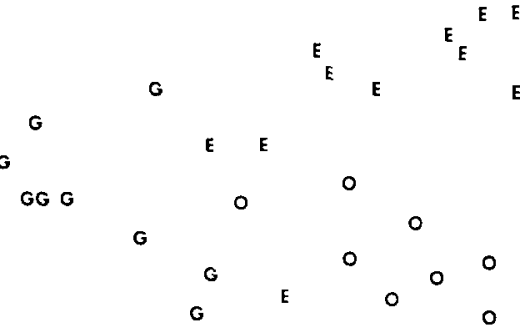

o

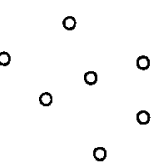

$0^{0}$

G

o

First Discriminant

Figure 1. The three-way discriminant analysis of the results obtained from foetal blood-gas analysis, indicating that the three series of results are separate and identifiable.

$\mathrm{G}=$ General anaesthesia; $\mathrm{E}=$ Epidural-air, $\mathrm{O}=$ Epidural-oxygen. 
the $\mathrm{PCO}_{2}$ of the $\mathrm{N}_{2} \mathrm{O}: \mathrm{O}_{2}$ series were significant measurements differentiating the three groups of patients.

Figure 1 illustrates the results of the three-way discriminant analysis carried out on the results obtained from foetal parameters at delivery. The infants in the general anaesthetic (G), epidural-oxygen(o), and epidural-air (E) are clearly separated into groups, indicating that statistically each group of neonates is different and identifiable on the basis of the variables measured in this study.

Table III outlines the summary of the mean foetal blood-gas analysis. Apgar scores and time to sustained respirations are shown in Table IV.

Orthogonal two-way discriminant analysis of the foetal parameters in the epidural and general anaesthetic series selected seven variables which helped distinguish the two groups of infants. These are the umbilical venous $\mathrm{Po}_{2}$ and $\mathrm{PCO}_{2}$; umbilical arterial $\mathrm{pH}$ and $\mathrm{PCO}_{2}$, and base deficit; the one minute Apgar score and the time to sustained rhythmic respirations.

Similar two-way discriminant analysis of the epidural-oxygen and epidural-air series selected five variables which differentiated the two sets of results. These measurements are umbilical vein $\mathrm{Po}_{2}$, umbilical artery $\mathrm{Po}_{2}, \mathrm{PCO}_{2}$ and base excess, and the TSR.

TABLE III

The Results of Foetal Blood-Gas Analysis $(\quad)= \pm \mathrm{SD}$

MEAN FETAL BLOOD-GAS ANALYSIS

\begin{tabular}{|c|c|c|c|c|c|c|}
\hline & \multicolumn{3}{|c|}{ UMBILICAL VEIN } & \multicolumn{3}{|c|}{ UWBILICAL ARTERY } \\
\hline & $\begin{array}{l}\text { EPIDURAL- } \\
\text { OXYGEN }\end{array}$ & EP IDURAL-AIR & $\begin{array}{l}\text { GENERAL } \\
\text { ANAESTHESIA }\end{array}$ & $\begin{array}{l}\text { EPIDURAL - } \\
\text { OXYGEN }\end{array}$ & ESIOURAL-AIR & $\begin{array}{l}\text { NERAL } \\
\text { AESTHESIA }\end{array}$ \\
\hline $\begin{array}{l}\mathrm{Po}_{2} \\
M M \text { HG }\end{array}$ & $35(6)$ & $29(6)$ & $24(11)$ & $19(6)$ & $16(6)$ & $14(8)$ \\
\hline $\begin{array}{l}\mathrm{PcO}_{2} \\
\text { HM } \mathrm{HG}\end{array}$ & $38(3)$ & $37(6)$ & $45(7)$ & $45(6)$ & $43(9)$ & $51(9)$ \\
\hline $\mathrm{pH}$ & $7.334(.032)$ & $7.316(.086)$ & $7.275(.070)$ & $7.278(.030)$ & $7.268(.078)$ & $7.221 \quad(.070)$ \\
\hline $\begin{array}{l}\text { BASE } \\
\text { EXCESS } \\
\text { MEq/L }\end{array}$ & $-5.285(2.074)$ & $-6.854(3.337)$ & $-6.792(3.008)$ & $-6.662(2.617)$ & $-8.085(3.473)$ & $-8.092(3.419)$ \\
\hline
\end{tabular}

TABLE IV

Apgar Scores and Time to Sustained Respirations $(\quad)= \pm$ SD APGAR SCORES AND TIME TO SUSTAINED RESPIRATION

\begin{tabular}{|c|l|l|l|}
\hline & $\begin{array}{l}\text { EPIDURAL - } \\
\text { OXYGEN }\end{array}$ & $\begin{array}{l}\text { EPIDLRAL - } \\
\text { AIR }\end{array}$ & $\begin{array}{l}\text { GENERAL } \\
\text { ANAESTHESIA }\end{array}$ \\
\hline APGAR I MINUTE & $8.1(0.8)$ & $8.2(2.0)$ & $5.5(2.7)$ \\
5 MINUTES & $9.6(0.5)$ & $9.5(1.1)$ & $8.5(1.8)$ \\
\hline $\begin{array}{l}\text { TIME TO } \\
\text { SUSTAINED RYTHMIC } \\
\text { (SEIRATIONS }\end{array}$ & $22.0(11.5)$ & $45.5(60.0)$ & $167.0(167.0)$ \\
\hline
\end{tabular}




\section{Discussion}

The high maternal oxygen tensions in the epidural-oxygen series are not unexpected, but the mean value of 364.0 (111.0) $\mathrm{mm} \mathrm{Hg}$ is less than one would theoretically anticipate with an inspired oxygen concentration of 100 per cent. In a recent study utilizing 50 per cent inspired oxygen, Houle ${ }^{14}$ found unexpectedly low maternal oxygen tensions. Others ${ }^{15}$ have confirmed this finding. The reasons are likely ventilation-perfusion abnormalities secondary to an elevated diaphragm caused by the presence of the foetus in utero, and the insertion of abdominal packs and surgical retraction.

All 3 groups of patients showed respiratory alkalosis prior to surgery. This has been noted by others, ${ }^{16}$ and is due to alveolar hyperventilation which may be hormonally influenced. ${ }^{17}$ While there was no change in the mean carbon dioxide tensions in the epidural group, the $\mathrm{PCO}_{2}$ in the $\mathrm{N}_{2} \mathrm{O}: \mathrm{O}_{2}$ group increased from a control tension of 25.0 (5.0) $\mathrm{mm} \mathrm{Hg}$ to 32.0 (4.0) $\mathrm{mm} \mathrm{Hg}$ at delivery.

Tidal volumes of $7.5 \mathrm{ml} / \mathrm{kg}^{18}$ were chosen in an attempt to minimize the alveolar-arterial oxygen gradients found during constant volume ventilation, but less than the recommended respiratory frequency of 20 breaths per minute was employed to avoid maternal hyperventilation. By preventing further maternal hypocapnia, in these cases increasing the $\mathrm{PCO}_{2}$, disturbances of oxygen transfer across the placenta and changes in placental blood flow are theoretically avoided. ${ }^{19,20}$

An increase in $\mathrm{PCO}_{2}$ in patients who are not strenously hyperventilated has been confirmed by others. ${ }^{17}$ Although the maternal $\mathrm{PCO}_{2}$ at delivery was significantly greater than in either epidural series, none of the groups was below the level which Moya ${ }^{21}$ considers could cause a reduction in uterine blood flow.

The higher umbilical venous oxygen tension of the epidural group as a whole may not be surprising in view of the fact that one half of these infants were exposed to a very high maternal-foetal oxygen gradient. Newman ${ }^{22}$ has shown that an increase in maternal oxygen tension of $100 \mathrm{~mm} \mathrm{Hg}$ or greater is always followed by a rise in foetal oxygen tension. Althabe ${ }^{23}$ demonstrated an increase in foetal tissue oxygen tension when mothers were exposed to high oxygen tensions.

Similarly, the infants in the general anaesthetic series were exposed to higher carbon dioxide tensions in the maternal arterial blood. Newman ${ }^{24}$ and Stenger ${ }^{25}$ both reported that foetal $\mathrm{PCO}_{2}$ rose as the maternal arterial $\mathrm{PCO}_{2}$ increased.

The physiology of placental gas exchange has been excellently reviewed. ${ }^{26,27}$ The passage of a gas across the placenta is influenced by the following mechanisms:

1. Diffusion in accordance with Fick's equation (surface area, pressure gradients, thickness of placental membrane, diffusion constant for the particular gas).

2. Rate of uterine and placental blood flow.

3. Haemoglobin concentrations in maternal and foetal blood.

4. Pattern of blood flow within the uterus:

(a) Concurrent 
(b) Countercurrent

(c) Multivillous

(d) Placental shunts

5. Foetal and maternal oxygen tensions and concentrations - foetal curve lies to the left of the maternal curve.

6. Factors influencing the maternal and foetal oxygen dissociation curves, $-\mathrm{pH}$ and $\mathrm{CO}_{2}$ transfer.

We will discuss our results in the light of the last two mechanisms since the influence of the other factors is unknown in these cases. The foetal oxygen dissociation curve rests to the left of the maternal curve at the same temperature and $\mathrm{pH}$ (Figure 2). The oxygen dissociation curve shifts to the right with an increase in blood hydrogen ion concentration. A shift to the right lowers the affinity of haemoglobin for oxygen and results in an increase in oxygen tension.

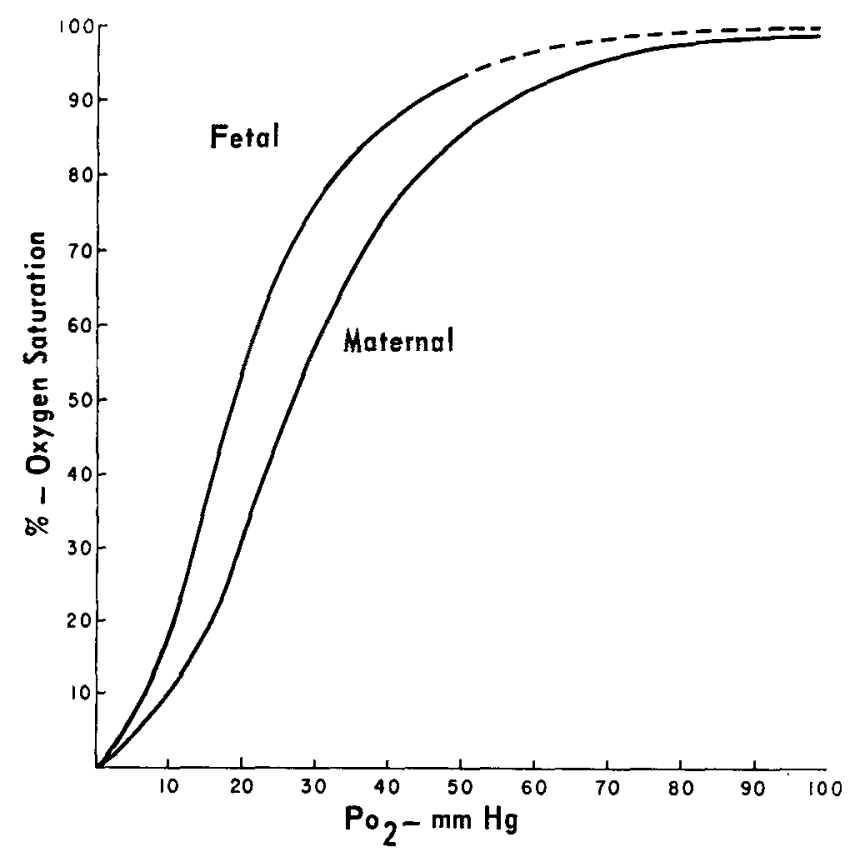

Frgure 2. The relationship between the foetal and maternal oxygen dissociation curves.

Foetal carbon dioxide and fixed acids diffuse into the maternal blood as it flows past the placental gas exchange sites. This has the effect of lowering plasma $\mathrm{pH}$ on the maternal side of the placenta, thus decreasing affinity of haemoglobin for oxygen and increasing $\mathrm{Po}_{2}$ (Bohr effect). This loss of $\mathrm{CO}_{2}$ and fixed acids from the foetal blood raises foetal $\mathrm{pH}$ and causes the haemoglobin dissociation curve to shift to the left, thus increasing the ability of the foetus to take up oxygen.

The infants delivered after general anaesthesia had a lower mean arterial $\mathrm{pH}$ than the epidural group due to a respiratory and metabolic acidosis. It is in the 
former group that we would expect a greater diffusion of carbon dioxide and fixed acids across the placenta, and therefore a greater shift to the right in the maternal oxygen dissociation curve. Although this might well have occurred, any advantage the $\mathrm{N}_{2} \mathrm{O}: \mathrm{O}_{2}$ group received due to the increased maternal oxygen tension was not as important in gas exchange as the extremely high gradient produced by the maternal inhalation of oxygen in one of the epidural groups. Other factors must be influencing the passage of oxygen because even though the maternal-foetal gradient was greater in the $\mathrm{N}_{2} \mathrm{O}: \mathrm{O}_{2}$ series than in the epiduralair series, the umbilical vein $\mathrm{Po}_{2}$ in the latter series was higher.

It is difficult to explain the difference in the carbon dioxide tensions of the umbilical vessels in the epidural and general anaesthetic groups. We can consider carbon dioxide exchange in terms of the Haldane effect. When blood takes up oxygen, its affinity with carbon dioxide decreases and carbon dioxide tension rises (Figure 3). Foetal blood as it becomes oxygenated during its passage through the intervillous space has an increase $\mathrm{Pco}_{2}$ (Figure 3, 2a, to $2 b$ ). Conversely maternal blood, on giving up oxygen during exchange, has a greater capacity to hold carbon dioxide (Figure $3,1 a$, to $1 b$ ). This process is partly negated by the concurrent exchange of standard bicarbonate (Figure 3) ${ }^{26}$ The loss of fixed acids from the foetus during placental exchange increases the capacity of the foetal blood for carbon dioxide without change in partial pressure (Figure $3,2 c$ to $2 b$ ). ${ }^{26.27}$

Other factors influencing carbon dioxide transfer are similar to those previously listed for the transfer of oxygen across the placenta, with the additional consideration of the placental production of carbon dioxide and fixed acids.

The epidural group, since it has a higher umbilical venous oxygen tension and saturation, has a decreased capacity to combine with carbon dioxide (Haldane effect). On the other hand, because this group contains less fixed acids, as evidenced by a higher $\mathrm{pH}$, it can combine with more carbon dioxide without changing the carbon dioxide tension. The infant's haemoglobin in the $\mathrm{N}_{2} \mathrm{O}: \mathrm{O}_{2}$ group, being less saturated with oxygen, theoretically has a greater number of sites for carbon dioxide binding. However, the fact that these infants have a greater amount of fixed acid as evidenced by the lower umbilical artery $\mathrm{pH}$ and greater base deficit means that the umbilical arterial blood has a lesser carbon dioxide capacity for that particular oxygen saturation. Since the Haldane effect has a greater influence on the carbon dioxide dissociation curve than the effect of shifts of fixed acids and standard bicarbonate, the lower carbon dioxide tensions of the epidural series could possibly be related to the displacement of the carbon dioxide curve. The higher maternal-foetal carbon dioxide tension gradient in the $\mathrm{N}_{2} \mathrm{O}: \mathrm{O}_{2}$ series presumably exerted a greater influence on the umbilical venous $\mathrm{P}_{\mathrm{CO}_{2}}$ than the other conditions causing a shift in the carbon dioxide dissociation curve. The weight of these factors is difficult to assess in view of the influences previously enumerated which alter diffusion across the placenta.

Umbilical arterial blood gas analyses reveal that the general anaesthetic group had a relative respiratory and metabolic acidosis. The umbilical arterial blood reflects the condition of the neonate. ${ }^{.8}$ The statistical method employed distinguished these acid-base differences between the entire epidural group and the 


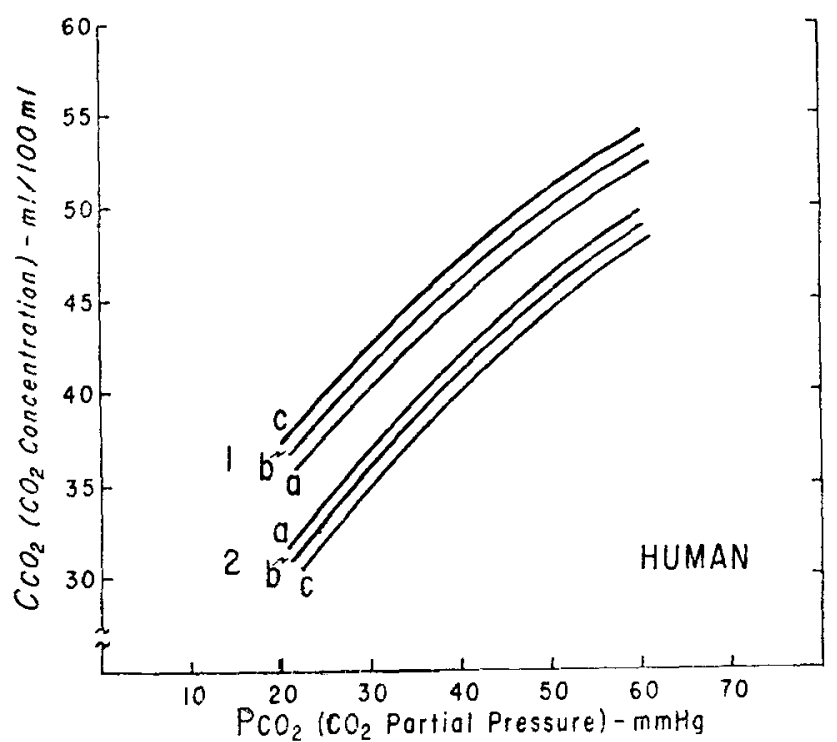

After Metcalfe, Bartels, Moll, Physiol. Rev. 782-838, 1967, Fig. 22

Figure 3. The carbon dioxide curves of maternal $(1 a, b, c)$ and foetal $(2 a, b, c)$ blood showing the influence of oxygenation and standard bicarbonate on the position of the carbon dioxide dissociation curve -

la uterine arterial blood

lb uterine venous blood

1c maternal blood; - venous oxygen saturation as $\mathrm{lb}$ and arterial standard bicarbonate concentration as la.

2a umbilical arterial blood

$2 \mathrm{~b}$ umbilical venous blood

$2 \mathrm{c}$ umbilical venous blood; arterial standard bicarbonate concentration as in $2 a$.

Oxygenation of maternal and foetal blood shifts the respective carbon dioxide dissociation curves downwards showing a decreased affinity of blood for carbon dioxide; curves shifts from $1 \mathrm{~b}$ to $1 \mathrm{a}$ and $2 \mathrm{a}$ to $2 \mathrm{~b}$.

Raising standard bicarbonate concentration and decreasing the level of fixed acids shifts the curves upwards $1 \mathrm{~b}$ to $\mathrm{Ic}$ and $2 \mathrm{c}$ to $2 \mathrm{~b}$ demonstrating an increased affinity of blood for carbon dioxide.

$\mathrm{N}_{2} \mathrm{O}: \mathrm{O}_{2}$ group. In fact, the base excess of the epidural-air and the $\mathrm{N}_{2} \mathrm{O}: \mathrm{O}_{2}$ groups are similar, the $\mathrm{pH}$ differences being due to the higher $\mathrm{PCO}_{2}$ in the general anaesthetic group.

The lower one minute Apgar scores and the longer time to sustained respirations in the $\mathrm{N}_{2} \mathrm{O}: \mathrm{O}_{2}$ group further demonstrates that this group of infants was depressed relative to the whole epidural series.

In comparing the infants delivered after epidural-air or epidural-oxygen analgesia, the outstanding observations were the differences in the umbilical venous and arterial oxygen tensions. The higher umbilical venous $\mathrm{Po}_{2}$ of the epiduraloxygen series is due to a very large maternal-foetal oxygen gradient which substantially aided diffusion of oxygen across the placenta. The other factors influencing 
the passage of oxygen are of secondary consideration in view of this large oxygen gradient. Despite the oxygen utilization which occurred during the passage of the blood through the foetal circulation a significantly higher umbilical arterial oxygen tension was found in the epidural-oxygen group. This results from a greater initial supply of oxygen to the foetus in the epidural-oxygen series and the extra margin of oxygen could be of critical importance to the foetus at risk.

Rorke $^{15}$ has shown that the umbilical venous and arterial oxygen tensions rise with an increase in maternal oxygen tension, until the inspired oxygen concentration is 66 per cent, after which there is a decline in the umbilical oxygen tensions. The umbilical venous $\mathrm{Po}_{2}$ of $35 \mathrm{~mm} \mathrm{Hg}$ in the epidural-oxygen series is less than that found by Rorke ${ }^{15}$ and Houle ${ }^{14}$ who utilized 66 per cent and 50 per cent inspired oxygen concentrations. The reasons for this may be haemodynamic alterations in the placental vessels protecting the foetus from hyperoxia. ${ }^{29}$

The higher umbilical arterial $\mathrm{PCO}_{2}$ in the epidural-oxygen series is in part due to the previously described Haldane effect. The haemoglobin molecule in this group of infants carried a greater amount of oxygen thereby dispossessing the carbon dioxide molecule of a site of attachment and so increased the $\mathrm{PCO}_{2}$.

The greater base deficit in the epidural-air series is indicative of the anaerobic metabolism which occurred in this group. This is probably due to a decreased availability of oxygen in these infants.

The longer time to sustained respiration in the epidural-air group was not reflected in a difference in the Apgar scores at one or five minutes. The earlier initiation of respiration in the epidural-oxygen group may be secondary to a higher arterial $\mathrm{PCO}_{2}$. However, due to the multiplicity of factors involved in the onset of respiration in the newborn, ${ }^{30}$ precise reasons cannot be given.

The incidence of hypotension after epidural anaesthesia for caesarean section has been reported as 47 per cent. ${ }^{31}$ Hypotension occurred in six and seven patients in the epidural-oxygen and epidural-air groups respectively.

\section{Conclusion}

In considering anaesthesia for elective caesarcan section, epidural analgesia appears to be the anaesthetic of choice in contrast to general anaesthesia. Neonates born to mothers given epidural analgesia have a lesser degree of acidosis, and a better degree of oxygenation which are demonstrated by more favourable one minute Apgar and TSR scores.

Moreover, in comparing epidural-air and epidural-oxygen analgesia, infants born in the latter group demonstrated higher venous and arterial oxygen and arterial carbon dioxide tensions, while those in the former group had a greater degree of metabolic acidosis. The addition of oxygen to the inspired air was related to a group of neonates whose acid-base parameters were more acceptable and who initiated spontaneous respirations at a shorter interval after birth.

\section{ACKNOWLEDGEMENTS}

We wish to thank Astra Chemicals Limited, Mississauga, Ontario, for support in carrying out this project. 
Appreciation is expressed to Professor F. D. K. Liddell, Department of Epidemiology and Health, McGill University, for the statistical analysis of the data obtained in this study.

\section{RÉSUMÉ}

Nous avons étudié trois groupes de 13 malades et nouveaux-nés au cours de césariennes électives faites sous anesthésie avec $\mathrm{N}_{2} \mathrm{O}, \mathrm{O}_{2}$ et épidurale. La moitié $\mathrm{du}$ groupe fait à l'épidurale a reçu de l'oxygène additionnel par masque.

Nous avons noté les paramètres suivants: Acide-base, score Apgar, le délai du début de la respiration.

Pour la césarienne élective, l'analgésie épidurale semble être l'anesthésie de choix. Le groupe des enfants nés sous épidurale a un degré d’acidose inférieur et une meilleure oxygénation que le groupe né sous anesthésie générale.

L'addition d'oxygène augmente les tensions d'oxygène dans la veine ombilicale et dans le sang artériel, ce qui constitue une réserve additionnelle importante d'oxygène.

\section{REFERENCES}

1. Cate, N. R. \& Nelson, H. B. A Critical Review of 965 Cesarean Sections. Pacific Med. Surg. 73: 365 (1965).

2. Supplement to The Second Report of the Perinatal Mortality Study in Ten University Teaching Hospitals. Ontario, Canada. The Ontario Department of Health (1967).

3. Low, J. A. Acid-Base Assessment of the Fetus Delivered by Elective Cesarean Section in the Normal Obstetric Patient. Obstet. Gynec. 25: 28 (1965).

4. Stenger, V. G.; Andersen, T.; Eitzman, D.; \& Prystowsky, H. Extradural Anesthesia for Cesarean Section: Physiologic and Biochemical Observations. Obstet. Gynec. 25: 802 (1965).

5. Stenger, V. G.; Blechner, J. N.; Andersen, T. W.; Eitzman, D. V.; Cestaric, E.; \& Prystowsky, H. Observations on Pentothal, Nitrous Oxide and Succinylcholine Anesthesia at Cesarean Section. Amer. J. Obst. Gynec. 99: 690 (1967).

6. Hollmén, A.; Jägerhorn, M.; \& Pystrnen, P. Foetal and Maternal Acid-Base Balance during Labour and at Birth. Acta anaesth. Scand. 11:341 (1967).

7. Hollmén, A. \& JÄGERHORN, M. The Effects of Epidural Anaesthesia and Cesarean Section on Foetal and Maternal Acid-Base Balance at Birth. Acta anaesth. Scand. 12: 115 (1968).

8. Bromage, P. R. Continuous Lumbar Epidural Analgesia for Obstetrics. C.M.A.J. 85: 1136 (1961).

9. Apgar, V. A Proposal for a New Method of Evaluation of the Newborn Infant. Anesth. \& Analg. 32: 260 (1953).

10. Apgar, V.; Holaday, D. A.; James, L. S.; Weisbrot, I. M.; Prince, C. E.; \& Weiss, I. Comparison of Regional and General Anesthesia in Obstetrics. J.A.M.A. 165: 2155 (1957).

11. Stggaard-Andersen, O.; Enget, K.; Jorgensen, K.; \& Astrup, P. A Micro Method for Determination of $\mathrm{pH}$, Carbon Dioxide Tension, Base Excess and Standard Bicarbonate in Capillary Blood. Scand. J. Clin. \& Lab. Invest. 12: 172 (1960).

12. SiggaArd-Andersen, O. \& Enget, K. A New Acid-Base Nomogram. Scand. J. Clin. \& Lab. Invest. 12: 177 (1960).

13. Clark, L. C. Monitor and Control of Blood and Tissue Oxygen Tensions. Trans. Amer. Soc, art. intern. Org. 2: 41 (1956).

14. Houle, G. L.; Fox, G. S.; \& Gertel, M. Methoxyflurane: Clinical and Laboratory Studies during Cesarean Section. Anesth. \& Analg. 48: 1011 (1969).

15. Rorke, M. J.; Davey, D. A.; \& Dutort, H. J. Foetal Oxygenation During Caesarean Section. Anesthesia. 23: 585 (1968).

16. Scott, D. B.; Lees, M. M.; Davie, T. T.; Slawson, K. B.; \& KerR, M. G. Observations on Cardiorespiratory Function during Cesarean Section. Brit. J. Anaesth. 41: 489 (1969).

17. Prowse, C. M. \& Gaensler, E. A. Respiratory and Acid-Base Changes During Pregnancy. Anesthesiology. 26: 381 (1965).

18. Bendixen, H. H. \& Laver, M. B. Hypoxia in Anesthesia: A Review. Clin. Pharmacol. Ther. 6: $510(1965)$. 
19. Moya, F. Considerations in Maternal and Placental Physiology. Anesth. \& Analg. 42: 661 (1963).

20. Morishima, H. O.; Moya, F.; Bassers, A. C.; \& Daniel, S. S. Adverse Effect of Maternal Hypocapnia on the Newborn Guinea Pig. Amer. J. Obstet. Gynec. 88: 524 (1964).

21. Moya, F.; Morishima, H. O.; Shnider, S. M.; \& JaMes, L. S. Influence of Maternal Hyperventilation on the Newborn Infant. Amer. J. Obstet. Gynec. 91: 76 (1965).

22. Newman, W.; McKinnon, L.; Phillips, L.; Paterson, P.; \& Woon, C. Oxygen Transfer from Mother to Fetus During Labor. Amer. J. Obstet. Gynec. 99: 61 (1967).

23. Althabe, O.; Schwarcz, R. L.; Pose, S. V.; Escarena, L.; \& Caldeyro-Barcia, R. Effects on Fetal Heart Rate and $\mathrm{Fetal}_{\mathrm{Po}_{2}}$ of Oxygen Administration to the Mother. Amer. J. Obstet. Gynec. 98: 858 (1967).

24. Newman, W.; Braid, D.; \& Wood, C. Fetal Acid-Base Status. Relationship Between Maternal and Fetal Pco.. Amer. J. Obstet. Gynec. 97: 43 (1967).

25. Stenger, V. G.; Eitzman, D.; Gessner, I.; Andersen, T.; \& Prystowsky, H. A Study of the Acid-Base Balance of the Fetus and Newborn and its Relation to that of the Mother. Amer. J. Obstet. Gynec, 90:625 (1967).

26. Metcalfe, J.; Bartels, H.; \& Moll, W. Gas Exchange in the Pregnant Uterus. Physiological Reviews. 47: 782 (1967).

27. Bartels, H.; Moli, W.; \& Metcalfe, J. Physiology of Gas Exchange in the Human Placenta. Amer. J. Obstet. Gynec. 84: 1714 (1962).

28. Crawfond, S. J. Principles and Practice of Obstetric Anaesthesia. Blackwell Scientific Publications. Oxford. 250 (1965).

29. Dawes, G. S. \& Motr, I. C. Changes in $\mathrm{O}_{2}$ Distribution and Consumption in Foetal Lambs with Variations in Umbilical Blood Flow. J. Physiol. Lond. 170: 524 (1964).

30. Dawes, G. S. Fetal and Neonatal Physiology. Year Book Medical Publishers. Chicago. 129 (1969).

31. Fox, G. S. \& Houle, G. L. Transmission of Lidocaine Hydrochloride across the Placenta during Caesarean Section. Canad. Anaesth. Soc. J. 16: 135 (1969). 